\section{$\underset{\substack{\text { hommes } \\ \text { \& migrations }}}{ }$}

\section{Hommes \& migrations}

Revue française de référence sur les dynamiques

migratoires

$1302 \mid 2013$

Le Japon, pays d'immigration?

\title{
L'envolée des mariages mixtes : une trajectoire féminine de migration
}

\author{
Hélène Le Bail
}

\section{(apenEdition \\ Journals}

\section{Édition électronique}

URL : http://journals.openedition.org/hommesmigrations/2484

DOI : 10.4000/hommesmigrations.2484

ISSN : 2262-3353

Éditeur

Musée national de l'histoire de l'immigration

Édition imprimée

Date de publication : 1 avril 2013

Pagination : 74-75

ISBN : 978-2-919040-22-3

ISSN : $1142-852 X$

\section{Référence électronique}

Hélène Le Bail, «L'envolée des mariages mixtes : une trajectoire féminine de migration », Hommes \& migrations [En ligne], 1302 | 2013, mis en ligne le 31 décembre 2015, consulté le 01 mai 2019. URL : http://journals.openedition.org/hommesmigrations/2484; DOI : 10.4000/hommesmigrations.2484 


\section{L'ENVOLÉE DES MARIAGES MIXTES UNE TRAJECTOIRE FÉMININE DE MIGRATION}

par HÉLÈNE LE BAIL, chercheur en science politique, Maison franco-japonaise, UMIFRE 19 CNRS-MAEE

\section{Évolutions des couples mixtes et des trajectoires migratoires}

Comme dans les autres pays riches d'Asie de l'Est, les mariages mixtes (dans le sens binationaux) au Japon sont avant tout le fait d'unions entre des hommes locaux et des femmes originaires des pays voisins. Les mariages mixtes sont devenus un phénomène social, par exemple à Taiwan où ils ont représenté jusquà $32 \%$ de l'ensemble des mariages en 2003, ou encore plus de $40 \%$ des mariages à Singapour et 13,5 \% en Corée en 2005. Au Japon, en termes de statistiques et de chiffres absolus, les mariages mixtes ont atteint un maximum en 2006 (6,1\% de l'ensemble des mariages).

Tous ces pays ont aussi en commun d'avoir longtemps vu dominer l'image d'un couple mixte formé d'une femme du pays et d'un mari occidental. Aujourd'hui, le couple mixte, même si les statistiques ne permettent pas de déterminer avec précision les parcours migratoires, est avant tout le fruit de la mobilité de la femme. Une grande partie de ces mariages sont des mariages transfrontaliers arrangés grâce à des agences matrimoniales plus ou moins formelles ou par effet de migrations en chaîne.

Dans le cas du Japon, deux types de trajectoires dominent parmi les épouses étrangères de Japonais. Le premier type de trajectoire est celui des femmes venues au Japon depuis les années 1980 grâce à un visa "monde du spectacle" (entertainer). Au cours de leur séjour (en général des séjours courts et à répétition étant donné que ce visa est limité à six mois), elles ont rencontré un Japonais, souvent dans le cadre de leur travail dans des bars ou des clubs, et se sont mariées. Ce parcours concerne en grande majorité des Philippines, les plus nombreuses à venir travailler au Japon dans ce cadre, jusqu'aux restrictions imposées à partir de 2005 faisant chuter le nombre de permis de séjour "monde du spectacle".

Le second type de trajectoire est celui de la migration de mariage : la femme quitte son pays après le mariage, l'union lui permettant d'obtenir un visa et un permis de résidence dans le pays de son époux. Les mariages sont arrangés par bouche-à-oreille ou par des agences plus ou moins formelles qui organisent le voyage des candidats pour participer à des rencontres de groupe ou des entrevues éclairs avec plusieurs femmes.

Les évolutions des couples types et des trajectoires migratoires font l'objet d'une mise en scène humoristique et pertinente par les auteurs de mangas. Au début des années 2000, le grand succès sur le thème des mariages mixtes a été le manga 


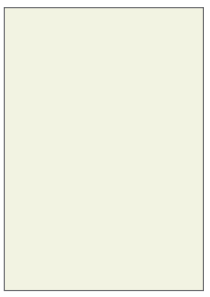

\section{Saori Oguri}

Dârin ha gaikokujin (Mon chéri est étranger)

Tokyo, Mediafactory, 2002. Le manga a été porté à l'écran en 2012 dans un film intitulé My Darling is a Foreigner.

autobiographique de Saori Oguri intitulé Mon chéri est étranger (2002) et qui évoque la vie quotidienne avec son mari américain.

Une décennie plus tard, les mariages entre hommes japonais et femmes asiatiques sont à leur tour le sujet de mangas autobiographiques.

En 2011, suite au succès de son blog, Junichi Inoue publie Journal d'une épouse chinoise. Le sous-titre en anglais A Chinese Wife and an Otaku Husband fait des deux membres du couple des figures types de la société japonaise contemporaine. L'auteur y raconte divers épisodes de leur vie de couple et, en particulier, celui de leur rencontre arrangée grâce à un Japonais lui-même installé et marié à Canton depuis des années. Il se met en scène dans toute sa banalité d'homme de 40 ans, otaku (personne qui reste enfermée chez elle et se consacre souvent à un hobby ou une passion), qui ne fait plus attention à lui depuis longtemps et n'imagine pas qu'une jeune Chinoise puisse le trouver intéressant. Le recueil met en scène une jeune épouse pleine de vie et de ressources et un couple heureux.

En 2012, c'est au tour de l'auteur de manga Musashi Maeda de raconter sa vie avec son épouse philippine. Cette fois, leur rencontre a eu lieu dans un "Philippine pub", un bar où travaillent des Philippines comme hôtesses grâce au visa "monde du spectacle".

De même que dans le manga de Inoue, l'épouse étrangère est mise en valeur par sa joie de vivre et son acharnement pour apprendre le japonais. Dans les deux cas, les traits culturels sont décrits avec humouretlabelle-familleestsourced'enseignements et de valeurs. Ces deux mangas très positifs ne reflètent pas, bien sûr, les conditions de vie et les relations familiales difficiles de beaucoup de couples mixtes, en particulier lorsque le mariage a été arrangé ${ }^{1}$. Ils offrent toutefois une alternative aux stéréotypes négatifs pesant sur les épouses venues des pays asiatiques.

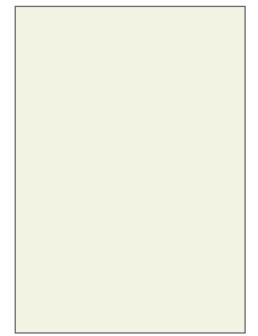

\section{Junichi Inoue}

Chûgoku yome nikki (Journal d'une épouse chinoise) Tokyo, Enterbrain, 2011

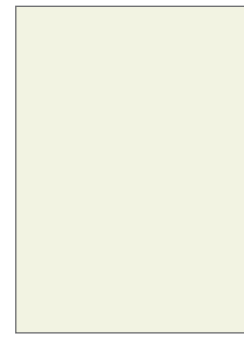

\section{Musashi Maeda}

Firipin tsuma yonkoma nikki (Comic strips d'une épouse philippine) Tokyo, PHP, 2012 